\title{
Flat ACL anatomy: fact no fiction
}

\author{
Rainer Siebold ${ }^{1,2}$
}

Published online: 8 October 2015

(C) European Society of Sports Traumatology, Knee Surgery, Arthroscopy (ESSKA) 2015

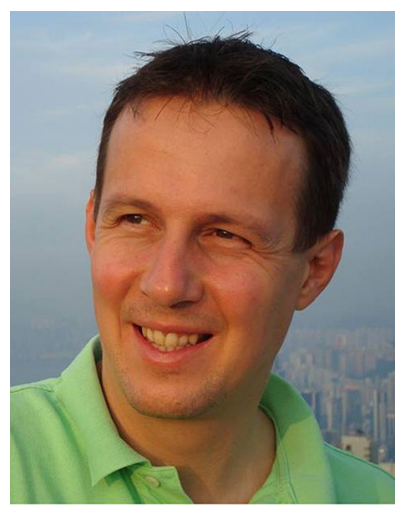

In 1836 Wilhelm and Eduard Weber published their detailed work on the anatomy and physiology of the lower extremity (Fig. 1) [25]. The anterior cruciate ligament (ACL) was shown to be flat in extension, twisted in flexion and aligned with the posterior femoral cortex. Nearly 100 years later (but also 100 years ago!), exactly in 1921 two French anatomists named Testut and Jacob described the flat ACL midsubstance and the close relationship between the anterior horn of the lateral meniscus and the tibial ACL insertion (Fig. 2) [24]. They beautifully showed that the bony insertion of the anterior root of the lateral meniscus was

Rainer Siebold

rainer.siebold@atos.de

http://www.hkf-ortho.de

1 HKF - International Center for Hip-Knee-Foot Surgery, ATOS Hospital Heidelberg, Bismarckstr. 9-15, 69115 Heidelberg, Germany

2 Institute for Anatomy and Cell Biology, Ruprecht-KarlsUniversity, Heidelberg, Germany just posterior to the ACL insertion in the area intercondylaris anterior. No bundles have been drawn.

At the beginning of the "modern" era of ACL surgery, such small details may not have played an important role for the orthopaedic society. Surgeons in their nature were fascinated by solving exciting technical issues like open and arthroscopic approach, transtibial and single-incision technique, bone tunnel placement and graft choice. So our ancestor's art was forgotten.

In 1938 Ivar Palmer was the first to describe bundles of the ACL and to perform an ACL reconstruction using a "double-bundle" technique [17]. Later Girgis et al. [8] divided the ACL into two functional parts: a smaller anteromedial band and a larger posterolateral band. This description was then used as a basis to understand the function of the different fascicles of the ACL $[4,18]$. Whereas some authors found three anatomical bundles $[2,14]$, others only described a single flat continuum of fascicles without any bundle structure $[3,16,26]$. Inspired by anatomical reports, the ACL "doublebundle" reconstruction was refined by innovative surgeons like Mott [12], Zaricznyj [28] and Muneta et al. [13].

The last 10 years experienced a "double-bundle boom" which was driven by many surgeons and scientists around the globe $[1,5-7,15,20,21,27]$. In an intension to better understand the ACL and to optimize surgical results, the anatomy and surgery was revisited. There was a strong interest to investigate the "double-bundle" structure with its anteromedial (AM) and posterolateral (PL) bundles and its insertion sites to support the surgical double-bundle concept. More than 600 articles have been published in PubMed related to the topic in recent years.

Simultaneously in 2006, the flat midsubstance and flat femoral ACL insertion was described by Mochizuki et al. [11]: "The configuration of the natural ACL midsubstance is not oval, but rather flat, looking like 'lasagne' about $15 \mathrm{~mm}$ in length and about $5 \mathrm{~mm}$ in width after removal of the surface 
Fig. 1 Drawings of Wilhelm and Eduard Weber, 1836 [25]

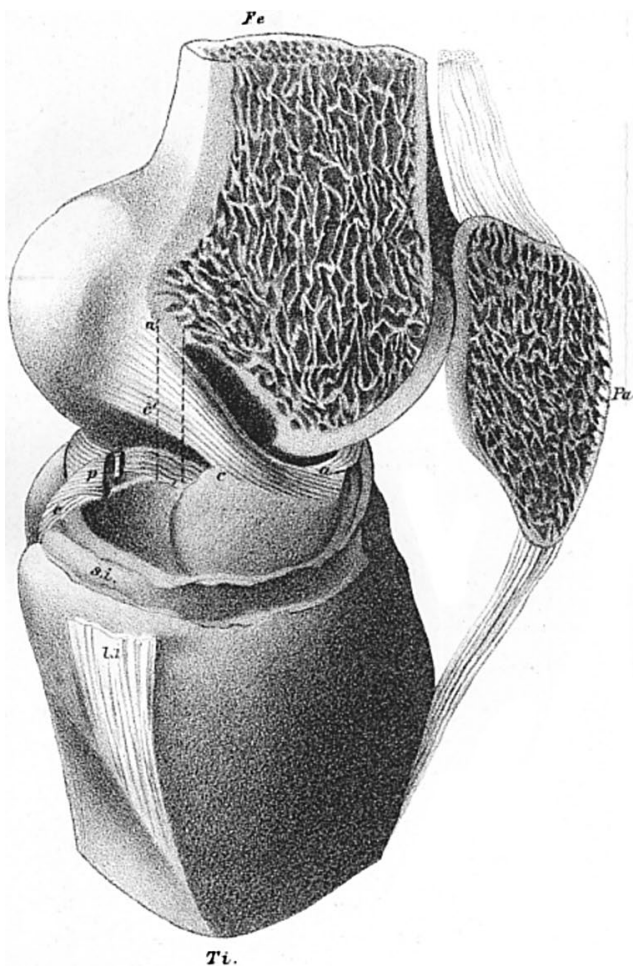

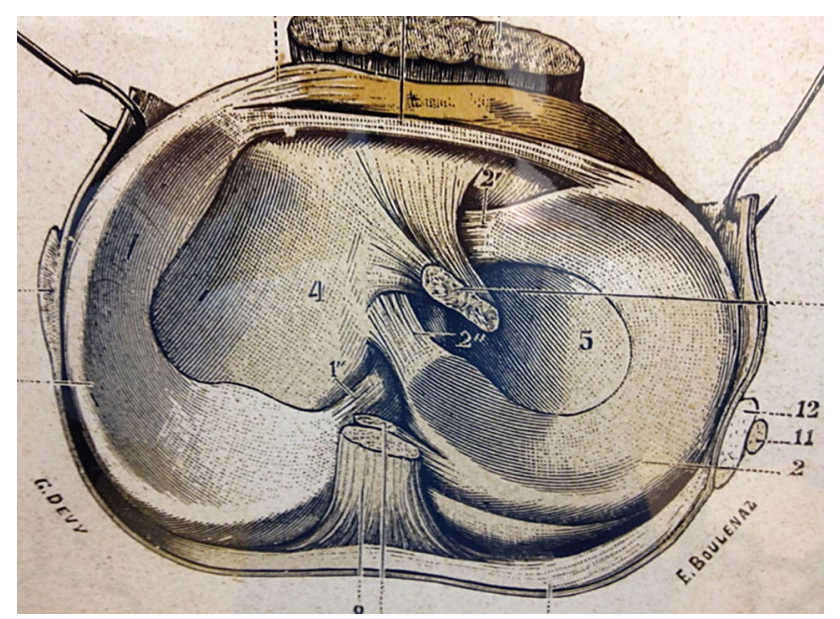

Fig. 2 Findings of Testut and Jacob, 1921 [24], showing flat midsubstance of ACL and tibial relationship between $\mathrm{ACL}$ and lateral Meniscus

membrane. The femoral insertion was found to be very similar to the flat midsubstance configuration after the ligament surface membrane was removed from the attachment site". In 2010 Iwahashi et al. [9] reconfirmed above findings and divided the femoral ACL insertion into "direct" and "indirect" ones. Sasaki et al. [19] found a 4-layered structure of the direct insertion, and again Mochizuki et al. [10] pointed out that it "is difficult to reconstruct the natural" (indirect) "fanlike extension fibres by creating a tunnel although the midsubstance fibres can be reconstructed by such procedure". In contrast to dissections from Europe and USA, none of these 4 groups did describe any ACL bundles.

It was at the ACL study group meeting 2012 in Jackson Hole when Robert Smigielski surprised the ACL specialists by stating that the "ACL is a ribbon". His group had just reconfirmed the Japanese findings of the flat midsubstance and femoral direct insertion of the ACL by artful anatomical dissections in 111 fresh-frozen cadaver knees [23]. They also rediscovered the "lost treasure" of the tibial relationship between ACL and lateral meniscus described by Testut and Jacob in 1921.

Smigielski investigated the insertion of the ACL midsubstance to the tibia and found a "C-shape" alignment of the midsubstance fibres anterior and along the medial tibial spine (ACL study group meeting 2012 in Jackson Hole). This finding was reconfirmed macroscopically in 2014 by Siebold et al. [22] using magnifying lenses and by histological investigations in 2015 (accepted for publication in Knee Surg Sports Traumatol Arthrosc). Like the Japanese, both European groups did not find any ACL bundles. To adapt the terminology, the authors suggested to use the term "ACL fibres" for anatomical descriptions and the term "ACL bundles" only in the surgical context of ACL "double-bundle" reconstruction [22, 23]. Like on the drawing from Testut and Jacob [24], both groups could not find any tibial posterolateral inserting ACL fibres [22]. Therefore Siebold et al. [22, 23] proposed to change the term "posterolateral (PL)" ACL fibres into "posteromedial (PM)" fibres according to the tibial insertion site. Above anatomical findings are published in this KSSTA issue. 
What may be the implementations to achieve better clinical results after ACL reconstruction? Further investigations in young cadavers may be wise to reconfirm the flat ACL anatomy in the population between 20 and 30 years. We may also aim for a flat "ribbon-like" reconstruction to mimic the flat ACL anatomy. For the moment, this may be best achieved with a flat patella tendon graft, a flat quadriceps tendon graft or a flat DB ACL reconstruction. As latter is very difficult, our group is currently working on an easier flat reconstruction with a flat semitendinosus tendon. Finally, for ACL reconstruction using a "double-bundle" technique, it may be recommended to change the tibial "PL" bone tunnel position into a "PM" one [22].

We never know, if something becomes better when we change it.

But we know very well, that we have to change if we want to improve.

Dante (1265-1321)

\section{References}

1. Adachi N, Ochi M, Uchio Y, Iwasa J, Kuriwaka M, Ito Y (2004) Reconstruction of the anterior cruciate ligament. Single-versus double-bundle multistranded hamstring tendons. J Bone Joint Surg Br 86(4):515-520

2. Amis AA, Dawkins GP (1991) Functional anatomy of the anterior cruciate ligament. Fibre bundle actions related to ligament replacements and injuries. J Bone Joint Surg Br 73(2):260-267

3. Arnoczky SP (1983) Anatomy of the anterior cruciate ligament. Clin Orthop Relat Res 172:19-25

4. Arnoczky SP, Warren RF (1988) Anatomy of the anterior cruciate ligaments. In: Feagin JA (ed) The crucial ligaments. Churchill Livingstone, London, pp 179-195

5. Cha PS, Brucker PU, West RV, Zelle BA, Yagi M, Kurosaka M, Fu FH (2005) Arthroscopic double-bundle anterior cruciate ligament reconstruction: an anatomic approach. Arthroscopy 21(10): 1275

6. Colombet P, Robinson J, Christel P, Franceschi JP, Djian P, Bellier G, Sbihi A (2006) Morphology of anterior cruciate ligament attachments for anatomic reconstruction: a cadaveric dissection and radiographic study. Arthroscopy 22(9):984-992

7. Fu FH, Shen W, Starman JS, Okeke N, Irrgang JJ (2008) Primary anatomic double-bundle anterior cruciate ligament reconstruction: a preliminary 2-year prospective study. Am J Sports Med 36(7):1263-1274

8. Girgis FG, Marshall JL, Monajem A (1975) The cruciate ligaments of the knee joint. Anatomical, functional and experimental analysis. Clin Orthop Relat Res 106:216-231

9. Iwahashi T, Shino K, Nakata K, Otsubo H, Suzuki T, Amano H, Nakamura N (2010) Direct anterior cruciate ligament insertion to the femur assessed by histology and 3-dimensional volume-rendered computed tomography. Arthroscopy 26(9 Suppl):S13-20

10. Mochizuki T, Fujishiro H, Nimura A, Mahakkanukrauh P, Yasuda K, Muneta T, Akita K (2014) Anatomic and histologic analysis of the mid-substance and fan-like extension fibres of the anterior cruciate ligament during knee motion, with special reference to the femoral attachment. Knee Surg Sports Traumatol Arthrosc 22(2):336-344
11. Mochizuki T, Muneta T, Nagase T, Shirasawa S, Akita KI, Sekiya I (2006) Cadaveric knee observation study for describing anatomic femoral tunnel placement for two-bundle anterior cruciate ligament reconstruction. Arthroscopy 22(4):356-361

12. Mott HW (1983) Semitendinosus anatomic reconstruction for cruciate ligament insufficiency. Clin Orthop Relat Res 172:90-92

13. Muneta T, Sekiya I, Yagishita K, Ogiuchi T, Yamamoto H, Shinomiya K (1999) Two-bundle reconstruction of the anterior cruciate ligament using semitendinosus tendon with endobuttons: operative technique and preliminary results. Arthroscopy 15(6):618-624

14. Norwood LA, Cross MJ (1979) Anterior cruciate ligament: functional anatomy of its bundles in rotatory instabilities. Am J Sports Med 7(1):23-26

15. Ochi M, Abouheif MM, Kongcharoensombat W, Nakamae A, Adachi N, Deie M (2011) Double bundle arthroscopic anterior cruciate ligament reconstruction with remnant preserving technique using a hamstring autograft. Sports Med Arthrosc Rehabil Ther Technol 3:30

16. Odensten M, Gillquist J (1985) Functional anatomy of the anterior cruciate ligament and a rationale for reconstruction. J Bone Joint Surg Am 67(2):257-262

17. Palmar I (1938) On the injuries to the ligaments of the knee joint. A clinical study. Acta chirurgica Scandinavica 81(53 suppl.):2-282

18. Reimann PR, Jackson DW (1987) Anatomy of the anterior cruciate ligament. In: Jackson DW, Drez D (eds) The anterior cruciate deficient knee. CV Mosby \& Co, St. Louis, pp 17-26

19. Sasaki N, Ishibashi Y, Tsuda E, Yamamoto Y, Maeda S, Mizukami H, Toh S, Yagihashi S, Tonosaki Y (2012) The femoral insertion of the anterior cruciate ligament: discrepancy between macroscopic and histological observations. Arthroscopy 28(8):1135-1146

20. Shino K, Nakata K, Nakamura N, Toritsuka Y, Horibe S, Nakagawa S, Suzuki T (2008) Rectangular tunnel double-bundle anterior cruciate ligament reconstruction with bone-patellar tendon-bone graft to mimic natural fiber arrangement. Arthroscopy 24(10):1178-1183

21. Siebold R, Dehler C, Ellert T (2008) Prospective randomized comparison of double-bundle versus single-bundle anterior cruciate ligament reconstruction. Arthroscopy 24(2):137-145

22. Siebold R, Schuhmacher P, Fernandez F, Smigielski R, Fink C, Brehmer A, Kirsch J (2014) Flat midsubstance of the anterior cruciate ligament with tibial "C"-shaped insertion site. Knee Surg Sports Traumatol Arthrosc. doi:10.1007/s00167-014-3058-6

23. Smigielski R, Zdanowicz U, Drwiega M, Ciszek B, Ciszkowska-Lyson B, Siebold R (2014) Ribbon like appearance of the midsubstance fibres of the anterior cruciate ligament close to its femoral insertion site: a cadaveric study including 111 knees. Knee Surg Sports Traumatol Arthrosc. doi:10.1007/ s00167-014-3146-7

24. Testut JL, Jacob O (1921) Précis d'anatomie topographique avec applications medico-chirurgicales. In: Doin. G (ed). Paris,

25. Weber W, Weber EF (1836) Mechanik der menschlichen Gehwerkzeuge: Eine anatomisch-physiologische Untersuchung. Dieterich, Göttingen

26. Welsh RP (1980) Knee joint structure and function. Clin Orthop Relat Res 147:7-14

27. Yasuda K, Kondo E, Ichiyama H, Tanabe Y, Tohyama H (2006) Clinical evaluation of anatomic double-bundle anterior cruciate ligament reconstruction procedure using hamstring tendon grafts: comparisons among 3 different procedures. Arthroscopy 22(3):240-251

28. Zaricznyj B (1987) Reconstruction of the anterior cruciate ligament of the knee using a doubled tendon graft. Clin Orthop Relat Res 220:162-175 